\title{
Reverse transcriptase inhibition: a way to defeat HIV
}

\author{
Vikas Kumar ${ }^{1}$, Harish Chandra Joshi² , I.P. Pandey ${ }^{1}$ \\ ${ }^{1}$ Department of Chemistry, Uttarakhand Technical University, India \\ ${ }^{2}$ Department of Chemistry, Graphic Era Deemed to be University, Dehradun, Uttarakhand, India
}

\begin{abstract}
Human immunodeficiency virus (HIV) induces disease in humans that is known as AIDS (acquired immunodeficiency syndrome). First AIDS cases were registered in 1981, and later, types of HIV infection, such as HIV-1 and HIV-2 were identified. HIV belongs to class of retroviruses, known as 'lentiviruses' and 'slow' viruses. A literature assessment was conducted through several reliable national and international journals as well as books and monographs, to investigate reverse transcriptase inhibitor (RI) from human immunodeficiency virus type 1 (HIV-1). Reverse transcriptase inhibitor limits the reverse transcriptase activity, which is considered the key enzyme of retroviral multiplication process, and eventually prevents infection and progression of retroviruses. In the current paper, more than twenty-five drugs were presented, which are used for management/treatment of AIDS. The aim of the present review was to summarize the latest update on reverse transcriptase inhibition. Lately, significant advancement has been observed on the growth of HIV-drugs targeting reverse transcriptase enzyme. There is a continuous increase in various compounds with anti-HIV activity and isolated from natural sources. The present review provided a selection of publications concerning the topic. Salient features of reverse transcriptase inhibitors (both NRTIs and NNRTI's) and possibility for development of new chemical entity were presented.
\end{abstract}

HIV AIDS Rev 2022; 21, 1: 3-9

DOI: https://doi.org/10.5114/hivar.2022.112762

Key words: human immunodeficiency virus (HIV), acquired immunodeficiency syndrome (AIDS), reverse transcriptase inhibitors (RTIs).

\section{Introduction}

Type 1 human immunodeficiency virus (HIV-1) is a cause of acquired immunodeficiency syndrome (AIDS), and the worldwide effects of AIDS continue to be serious. The Center for Disease Control and Prevention (CDC) estimated that, by the end of 2002, 42 million people were living with AIDS, out of which 38.6 million were adults and 3.2 million were children under the age of 15 . In 2002, 5 million new infections were reported by the World Health Organization (WHO). Almost 20,000 patients suffering from AIDS die each year. A recent survey from 2019 reported

Address for correspondence: Vikas Kumar, Uttarakhand Technical University, India, e-mail: vikasnagaich@gmail.com

that HIV/AIDS continues to have devastating health effects globally, with over 39 million HIV/AIDS-related deaths to date, and more than 36 million people living with HIV currently. The USA alone had spent 170 billion dollars on AIDS research from 1981 to 2005, and still investing over 20 billion dollars annually. An effective solution remains to be found despite these efforts. However, discovery of new drugs and combination therapy has been an important step forward in treatment.

In the early 1980s, HIV-1 was identified as the etiological agent of AIDS $[1,2]$. There is no cure for AIDS at this

Article history:

Received: 30.03 .2021

Revised: 22.05.2021

Accepted: 23.05.2021

Published: 15.01 .2022
International Journal of HIV-Related Problems

HIV \& AIDS

$R$ e vi e w 
time. A strong HIV treatment launched in the mid-1990s is a highly effective antiretroviral therapy (HAART), and consist of three or more distinct medicines to suppress the virus in combination [3].

HIV belongs to a class of retroviruses known as 'lentiviruses' and 'slow' viruses [4]. The infection process with these viruses is marked by a long interval of severe symptoms and an initial infection. Like all bacteria, HIV can only replicate in cells and replicate the cells. Retroviruses contain ribonucleic acid (RNA) genes, whereas deoxyribonucleic acid (DNA) is an associated molecule for the genes of humans and most other animals. HIV and other retroviruses use reverse transcriptase of enzyme once inside the cell to transform their RNA into DNA, which can be entered into DNA of human body [5]. In viral replication, the first stage is to attach a viral part to the host cell's CD4, and a coreceptor (CCR/CXCR4) is the first phase [6]. HIV virus enters the cell after the virus fuses with the host cell. When linked, it is necessary to discharge the content of one of several co-receivers, that is, two copies of viral RNA, for fusion process and for viral particle. HIV reverse transcriptase transforms the viral RNA into nucleic acid form within the cell's cytoplasm, in which the cell is carrying its' genes. A complete copy of DNA is produced and subsequently dilapidated $[7,8]$. Newly produced DNA of HIV move to the cell core to separate the viral DNA into the host's DNA through HIV integrate. Once the viral DNA is incorporated into the host cell, the cell creates viral proteins, if active. This virus is also called a virus. Abnormal immune activation is considered to be the main factor in development of the disease in present pathogenic HIV model by development of an activated CD4 $\mathrm{T}$ cell that can be targeted by HIV, resulting in immune depletion [9]. A positive correlation exists between the degree of activation of CD8 $\mathrm{T}$ cells and the risk of progression to AIDS [10]. In the absence of CD4 cell, the virus can continue for many years in latent phase [9]. The virus has a great deal of complex efforts to eradicate HIV in latently infected cells. For this reason, HIV-positive patients must continue with permanent antiviral therapy [11]. DNA-transcribed RNA, known as 'messenger RNA' (mRNA), is transferred to cytoplasm from the nucleus of the cell.

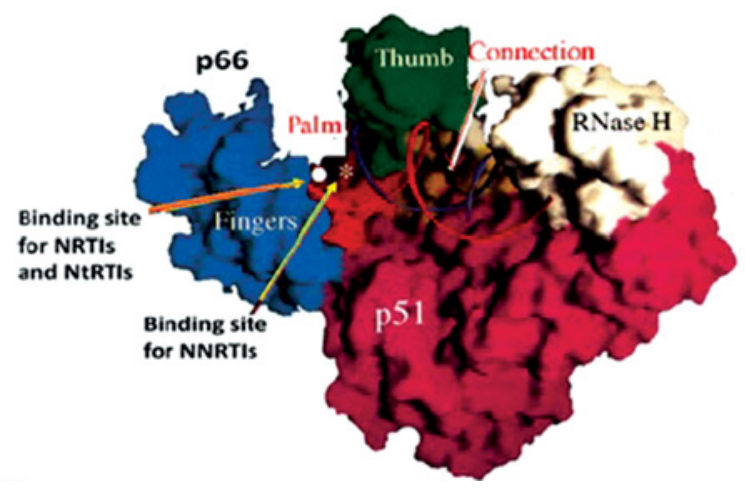

Figure 1. Reverse transcriptase
The mRNA virus takes over usual protein units of the cell and then begins to produce proteins of HIV virus by using HIV mRNA as a template once in the cytoplasm. This method is known as 'translation'. The protein sequence is transferred into RNA of mRNA molecules and the proteins are the virus core and envelope. The translation gene products are considerably larger than those comprising the final virus, and must be separated into smaller functional units. Gene products are reduced to size by viral protease. HIV protease is extremely HIV-specific and the aim of a group of HIV-treated drugs. Viral envelope proteins are spliced, and core proteins, RNA, and enzymes are located inside the membrane of the host cell. The virus pins the cell and 'buds' off $[7,8]$. Either chronically, over weeks, a single cell can produce thousands of HIV infectious particles, or as a single burst leading to death of the cell.

\section{Reverse transcription: a complex reaction}

Reverse transcription is a complex reaction and consist of various catalytic mechanism. Transfer-RNA3 ${ }^{\text {Lys }}$ act as a primer in the reaction and undergoes hybridization at the binding site (primer), i.e., at the fifth end of infected genome (viral genome). As a result, ssDNA (single-stranded) is formed; this relocates and hybridizes at the third end of genome (RNA). The next step after the strand relocation is the building up of DNA strand. Various enzymatic or catalytic mechanism involved during DNA synthesis are RNA primer with RNA-dependent DNA polymerization, DNA primer with RNA-dependent DNA polymerization, and functioning of ribonuclease $\mathrm{H}$. The function of ribonuclease $\mathrm{H}$ lies in hydrolysis of template of RNA. Ribonuclease $\mathrm{H}$ situates in reverse transcriptase enzyme, and this process occurs before strand transfer mechanism. Synthesis of second DNA strand also undergoes strand relocation or transfer mechanism [11].

\section{Reverse transcriptase inhibitors}

RTIs belong to an antiretroviral drug class used for treating HIV or HIV infections, and in some cases, hepatitis B (reverse transcriptase inhibitors). RTIs impede reverse transcriptase activity, a viral DNA polymerase needed for HIV and other repletion of retrovirus. RT is generated from a viral polyprotein that is processed through the virus protease to create two associated units (p66 and p51) of distinct lengths that mix in a stable asymmetric heterodimer [12], a prevalent amino terminus. Analysis of the RT crystal structure shows that p66 has two spatially separate domains, including polymerase and RNase $\mathrm{H}$. The polymerase domain demonstrates a heavily preserved, distinctive structure resembling a hand of a finger, composed of sub-domains (residues, 1-85 and 118-155), palm and thumb (residues, 86-117 and 156-237). Moreover, p66 includes the connecting sub-domain (residue, 319-426) and the domain RNase H (residue, 427-560) (Figure 1) [13, 14]. 
The p51 sub-unit lacks the domain RNase $\mathrm{H}$, but its' relative positions are distinct from that of the $\mathrm{p} 66$ polymerase domain. This is why the p51 sub-unit folds differently than p66. It has no enzyme activity while anchoring a proper folding of the p66 sub-unit that carries out all catalytic tasks. HIV-1 RT structure is for the differentiation of the two fields: p66 and p51.

NNRTIs RT are mainly accountable for a range of different functionalities, all of which are essential for a retro transcription, including RNA- and DNA-dependent synthesis of DNA, RNase $\mathrm{H}$ activity, strand transfer, and rand displacement synthesis. The extremely dynamic RT nature that enables RTs to spontaneously slide over lengthy distances of RNA: DNA and DNA: DNA duplexes in a single-protein, facilitates the existence of all these features, facilitating targeting the primary end of DNA polymerization, to access many sites promptly and therefore, to compensate for its' low process ability. RT sliding requires no nuclear hydrolysis energy, and it should be a thermally powered process [15]. It has been observed that RT can bind the nucleic acid substrates, labeled as RNase $\mathrm{H}$ cleavage skillful guidance and polymerase skilled guidance, to two distinct directions, to each and all, and that each enables one of the two RT enzymes related activity to catalyze [16]. These two binding modes are dynamically equilibrated and it has been shown that RT can change between the two orientations spontaneously and quickly without being separated from immutability. Small molecules as nucleotides, which stabilize the competent polymerase orientation or inhibit it, on reverse, can influence this fluctuation [17]. Together, shuttling and switching correspond to very complicate conformational modifications, which boost the replication effectiveness enormously, and combine DNA polymerization with RNA cleavage.

However, human immunodeficiency virus type-1 (HIV-1) reverse transcriptase (RT) is the primary target for HIV/ AIDS drug development [18]. Based on their chemical frameworks, reverse transcriptase inhibitors (RTIs) are of the following types:

- nucleoside analogue reverse transcriptase inhibitors (NRTIs or NARTIs),

- nucleotide analogue reverse transcriptase inhibitors (NtRTIs or NtARTIs),

- nucleoside analogue reverse transcriptase translocation inhibitor (NRTTIs),

- non-nucleoside analogue reverse transcriptase inhibitors (NNRTIs),

- non-nucleoside reverse transcriptase inhibitors (NNRTIs). In the late 1980s, discovery and development of NNRTIs began [19], with approval of four NNRTIs by regulatory authorities in late 2009, and clinical development of several others. NNRTIs are different from other classes, because of their chemical structure, which does not involve nucleoside ring in molecular structure, allowing for the drug to bind in a different binding side other than existing reverse transcriptase inhibitors (Figure 1).
Drug resistance rapidly evolves if NNRTIs are given as mono-therapy and, as a result, NNRTI compounds are often used for treatment of HIV infections in conjunction with other antiretroviral drugs [20]. Four NNRTIs are implemented into highly active antiretroviral therapy (HAART), including viramune, rescriptor, sustiva, and intelence. Since etiological agent for acquired immunodeficiency syndrome (AIDS) $[21,22]$ has been identified as human immunodeficiency virus (HIV), an unpredicted number of drugs for therapy of HIV-infected patients have been initially awarded [23].

This achievement in identification of efficient medicines is definitely unique in the therapy of viral infections, and combined with the use of this armamentarium in distinct combination therapeutics. However, the management of this disease remains complicated and challenged by issues, such as therapy efficacy surveillance, chronic drug administration toxicity, bad tolerability, growth of drug resistance, and treatment adjustment after errors in treatment [24]. For all these reasons, the quest for fresh inhibitors, which might have a distinct molecular mechanism or pattern of drug resistance, and may possibly have distinct drug-associated chronic toxicity, is a global health concern. The success of HIV infection treatment is certainly connected to intensive dissection of HIV life cycle, validation of several of its' steps to the end of medicine, and subsequent identification and development of several viral inhibitors against many of them $[23,24]$. Reverse transcriptase (RT) and virus-coding enzyme that convert ssRNA viral genome into DNA pro-virus, is one of the HIV proteins that is deeply characterized as main drug target, and is therefore imported into the nucleus of cells and incorporated with virus-coded integrities (IN) into host chromosome.

\section{Examples of first and second generation NNRTs}

To target reverse transcriptase, many marketed drugs have been approved, including high efficiency drugs. In Table 1, mostly first generation drugs are described, with indications for use and side effects.

Chemical structure and functional groups presented in active moiety, play an important role, hence the chemical structures of various drugs are shown in Figure 2.

\section{Nucleoside reverse transcriptase inhibitors (NRTIs)}

Nucleoside reverse transcriptase (NRTIs) inhibitors (NTRTIs) are nucleoside and nucleotide analogs that inhibit reverse transcriptase. HIV is an RNA virus that cannot be incorporated in the human cell nucleus into DNA, and therefore must be transcribed in 'reverse' form in DNA. Because RNA is not converted into DNA in mammalian cell, a viral protein is used to make RNA a specific target for inhibition. NRTIs are the chain terminators, which operate by stopping the incorporation of other nucleosides into the DNA chain once integrated, because 
Table 1. Examples of first and second generation NNRTs with their indications and side effects

\begin{tabular}{l|c|c|c}
\hline Drugs [Ref.] & Generation & Indication & Side effects \\
\hline Nevirapine [25] & $\begin{array}{c}\text { First generation drug, } \\
\text { FDA-approved in 1996 }\end{array}$ & $\begin{array}{c}\text { Used with one or more NRTs } \\
\text { for management of HIV } \\
\text { infection in developing } \\
\text { countries }\end{array}$ & Hepatotoxicity and rashes \\
\hline Delavirdine [26] & $\begin{array}{c}\text { First generation drug, } \\
\text { FDA-approved in 1997 }\end{array}$ & $\begin{array}{c}\text { Primary line of defense } \\
\text { in HAART }\end{array}$ & $\begin{array}{c}\text { Currently not used because } \\
\text { of resistance development }\end{array}$ \\
\hline Efavirenz [27] & $\begin{array}{c}\text { First generation drug, } \\
\text { FDA-approved in 1998 }\end{array}$ & $\begin{array}{c}\text { Effective for naïve patients } \\
\text { in HART treatment with two } \\
\text { nucleoside inhibitors }\end{array}$ & CNS side effects \\
\hline Etravirine [28] & Second generation drug & $\begin{array}{c}\text { Used for patients who } \\
\text { are already undergone } \\
\text { a treatment. Better } \\
\text { resistance profile, induces } \\
\text { greater genetic barrier }\end{array}$ & - \\
\hline $\begin{array}{l}\text { Rilpivirine, lersivirine, } \\
\text { IDX-899, and RDEA-428 [29-31] }\end{array}$ & Second generation drugs & $\begin{array}{c}\text { Riline act as a potential } \\
\text { drug candidate for naïve } \\
\text { patients }\end{array}$ & \\
\hline
\end{tabular}

of a 3' $\mathrm{OH}$ group non-integration. Both are competitive inhibitors of the substrate. For example, zidovudine, abacavir, lamivudine, emtricitabine, and tenofovir are currently applied [32]. There are currently seven clinically certified NRTIs for HIV infection therapy, including zidovudine, didanosine, zalcitabine, stavudine, lamivudine, abacavir, and emtricitabine. This combination of drugs was first published under a code sequence (BW A509U), 30-azido-30deoxythymidine (AZT) [33]. It was announced as an antiHIV agent that was the second most commonly reported suramin to prevent infectious HIV (T-limphotrophic type III/ lymphadenopathy-associated virus) documented as a hexasulfonate, just one year before AZT [34]. After AZT, several more 2', 3'-dideoxygenucleosides were reported to have inhibited HIV infectivity, including 2', 3'-dideoxyadenosine (ddA), 2', 3'-dideoxyguanosine (ddDG), 2', 3'-dideoxycytidine (ddC), and 2, 3-dideoxyminosine (dddI), respectively. At the end, two of these 2, 3, didanosine and zalcitabine, di-deoxy-nucleosides would be created as anti-HIV medicines. The finding that AZT is an inhibitor of HIV replication and how unexpected it may appear, may have led to a global search for new analogs of nucleosides as prospective anti-HIV agents. As a powerful anti-HIV agent in a number of labs across the globe, it is known as 2', 3-didehydro-2', 3'-dideoxythymidine ( $\mathrm{d} 4 \mathrm{~T}$ ) [35-38]. The pioneering work of Bernard Belleau (Soudeyns et al., 1991) and FTC, deriving from the attempts of $\mathrm{D}$, followed 3TC (2, 3-dideoxy-3thiacytidine) R.F., and Liotta [39] from Emory University. In the meantime, Susan Daluge and her peers defined abacavir (ABC) [40]. The same way as AZT [41], all NRTIs function, in which they serve as alternate substrates and competition inhibitors for naturally occurring substrates (dTTP, dCTP, dATP, or dGTP) follow their intra-cellular phosphorylation into their 5-triphosphate response [42, 43].
NRTIs, like with all antiretroviral agents, lead to a range of medicinal-resistant HIV-1 types that have a decreased susceptibility. Two excellently-elucidated mechanisms have been developed for drug resistance to NRTIs [44]. The first resistance mechanism influences binding and incorporation rates of incoming nucleotide analog, and mainly involves proteins in direct contact with incoming NRTI triphosphate. Mutations in these residues increase discrimination against natural triphosphates of NRTI triphosphate and, as a result, stop NRTIs from being incorporated into the nascent chain. The classic instance is $\mathrm{M} 184 \mathrm{~V} / \mathrm{I}$, which creates steric interference in appropriate binding of 3TC and FTC at HIV-1 RT site $[45,46]$, which is an instance of this mutation. The second mechanism for the drug resistance is reverse of the chain termination of pyrophosphate, which acts through removing by ATP of NRTI-tri phosphorolysis from the end of 3' of the nascent chain. A comprehensive study of this excision mechanism has been conducted and associated mutations are commonly known thymidine analog (TAMs). They promote pyro-phosphorolysis and encompass resistance against AZT and $\mathrm{d} 4 \mathrm{~T}[47,48]$. Resistance mutation of NRTIs was shown in a comparison with wild-specimen viruses to decrease the virus ' fitness and replicating ability to differing degrees [44].

\section{Salient features of reverse transcriptase inhibitors [47-50]}

Anti-retroviral drugs inhibit a complex reaction of 'reverse transcription', which is further divided into two broad categories, such as nucleoside reverse transcriptase inhibitors (NRTIs) and non- nucleoside reverse transcriptase inhibitors (NNRTIs). Both of these inhibitors have some major key differences in their characteristic features, which make 
<smiles>Cc1cc(C#N)cc(C)c1Oc1nc(Nc2ccc(C#N)cc2)nc(N)c1Br</smiles>

Etravirine

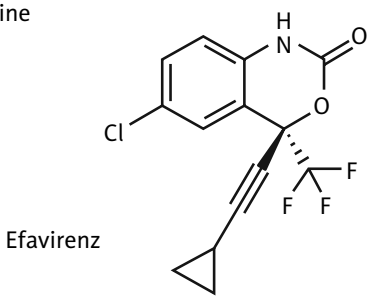

Figure 2. Non-nucleoside anti-HIV drugs

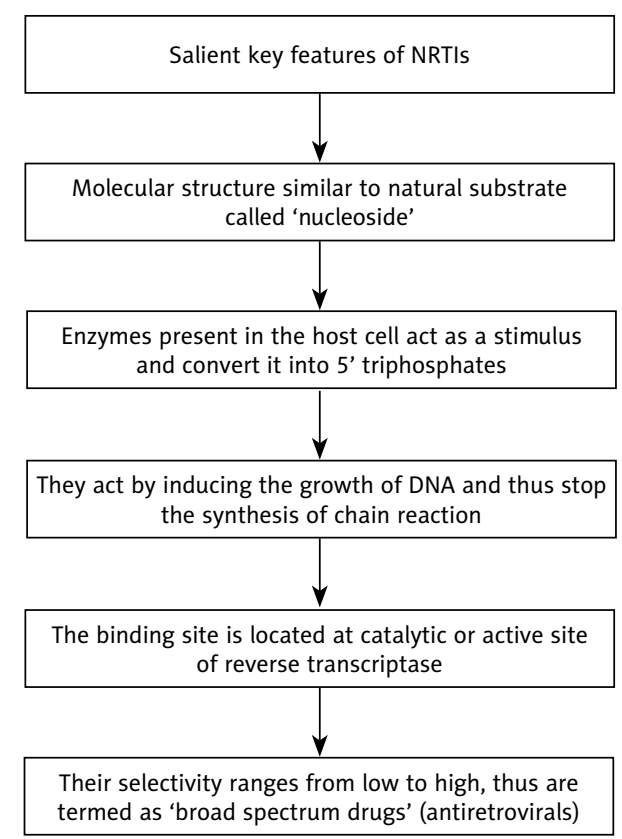

Figure 3. Salient features of reverse transcriptase inhibitors

their function different from each other (Figure 3). Recently, many papers showed a plant material as reverse transcriptase inhibitors.

\section{HIV test}

Long-term survival in patients with the virus and avoidance of further transmission to sexual or injectable drug sharing partners are pivotal for early HIV screening and detection. In 1987, the United States Public Health Service produced guidelines for HIV screening and counseling of patients with high-risk behaviors. According to the CDC's 2006<smiles>C=C(c1cc2cc(NS(C)(=O)=O)ccc2[nH]1)N1CCN(c2ncccc2NC(C)C)CC1</smiles>

Delavirdine<smiles>Cc1cc(/C=C/C#N)cc(C)c1Nc1ccnc(Nc2ccc(C#N)cc2)n1</smiles>

Rilpivirine

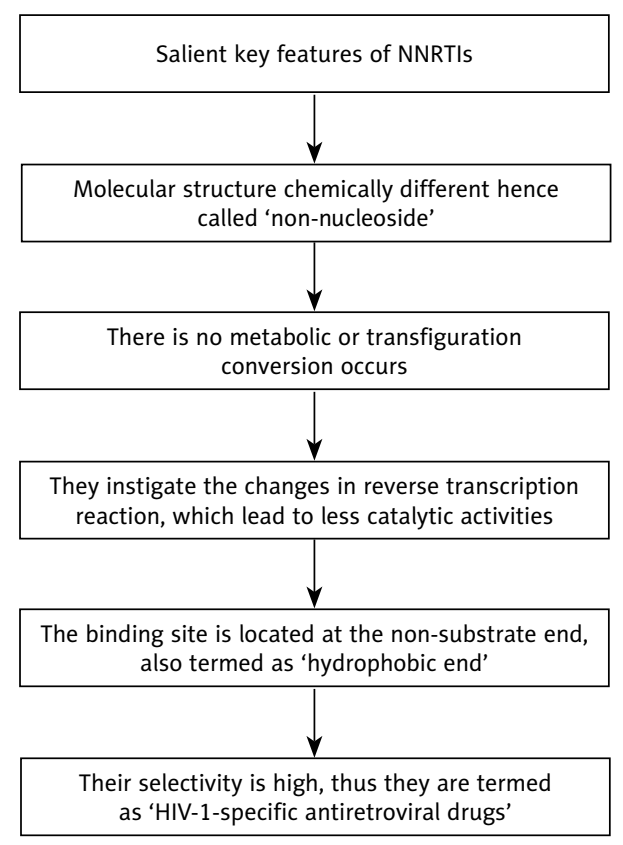

HIV test guidelines, HIV screening should be informed and checked for all patients in health facilities without risk variables [51]. HIV routine screening is a key instrument of public health to identify the virus in order to provide a therapy in advance of symptoms, and in order to decrease the chance of ongoing viral transmission. This strategy is referred to as 'opt-out screenings'. The FDA has endorsed blood tests for blood banks to detect antibodies to HIV-1 and HIV-2 using enzyme-like immunoassays. A latest research has been conducted to assess capacity of a variety of FDA-licensed tests in 240 human plasma samples gathered in two urban blood centers in Cameroon, a population with extremely common 
HIV genes and recombinant HIV strains. Findings showed that the tests were very sensitive for genetic variants emerging [52]. Currently, there are four FDA-authorized quick HIV tests in the market. The other two tests (Revel and UniGold Recombigen) can screen for HIV-1 only [53]. Two tests for these quickest HIV tests (OraQuick and Multispot) are available for screening for both HIV-1 and HIV-2. Currently, no counter fast-tests are available.

Primary target for the design of new anti-HIV drug is reverse transcriptase (RT) enzyme, which is a multifunctional enzyme in human immunodeficiency virus (HIV)-1 life cycle. Nucleoside RT inhibitors (NRTIs) and non-nucleoside transcriptase inhibitors (NNRTIs) are two classes of RT inhibitors that are prominently used in highly active antiretroviral therapy in combination with other anti-HIV drugs. However, the rapid emergence of drug-resistant viral strains has limited the successful rate of anti-HIV agents. The review was to provide a brief introduction into the two classes of drugs, with their pros and cons.

\section{Conclusions}

In the current report, HIV and its' related complications were taken as reference to investigate the existing best treatment options. In view of that the marketed drug is a choice for HIV treatment and sometimes express unwanted side effects, it is important to always be up-to-date in the research regarding new treatment choices. In the current review, more than twenty-five drugs were presented, which are used for the management/treatment of AIDS. Out of these drugs, approximately twelve belong to the category of reverse transcriptase inhibitors. It was the focus of this review and important references were taken into consideration. In the present review, reverse transcriptase inhibitors were found alarming as drugs, because of their potential adverse effects. The salient features of reverse transcriptase inhibitors (both NRTIs and NNRTIs) were found incorporating in an area of scope for the development of new chemical entity.

\section{Conflicts of interest}

The authors declare no conflict of interest.

\section{References}

1. Barré-Sinoussi F, Chermann JC, Rey F, et al. Isolation of a T-lymphotropic retrovirus from a patient at risk for acquired immune deficiency syndrome (AIDS). Science 1983; 220: 868-871.

2. Gallo RC, Salahuddin SZ, Popovic M, Shearer GM, Kaplan M, Haynes BF. Frequent detection and isolation of cytopathic retroviruses (HTLV-III) from patients with AIDS and at risk for AIDS. Science 1984; 224: 500-503.

3. Kohlstaedt LA, Wang J, Friedman JM, Rice PA, Steitz, TA. Crystal structure at 3.5 A resolution of HIV-1 reverse transcriptase complexed with an inhibitor. Science 1992; 256: 1783-1790.

4. Berger EA, Murphy PM, Farber JM. Chemokine receptors as HIV-1 coreceptors: roles in viral entry, tropism and disease. Annu Rev Immunol 1999; 17: 657-700.
5. Chiu IM, Yaniv A, Dahlberg JE, et al. Nucleotide sequence evidence for relationship of AIDS retrovirus to lentiviruses. Nature 1985; 317: 366-368.

6. Smith J, Daniel R. Following the path of the virus: the exploitation of host DNA repair mechanisms by retroviruses. ACS Chem Biol 2006; 1: 217-226.

7. Zheng YH, Lovsin N, Peterlin BM. Newly identified host factors modulate HIV replication. Immunol Lett 2005; 97: 225-234.

8. Potter SJ, Lacabaratz C, Lambotte O, Perez-Patrigeon S, Vingert B, Sinet M. Preserved central memory and activated effector memory CD4 T-cell subsets in human immunodeficiency virus controllers: an ANRS EP36 study. J Virol 2007; 81: 13904-13905.

9. Giorgi J, Hultin L, McKeating J, Johnson T, Owens B, Jacobson L. Shorter survival in advanced human immunodefciency virus type 1 infection is more closely associated with T lymphocyte activation than with plasma virus burden or virus chemokine coreceptor usage. J Infect Dis 1999; 179: 859-870.

10. Blankson J, Persaud D, Siliciano R. The challenge of viral reservoirs in HIV-1 infection. Annu Rev Med 2002; 53: 557-593.

11. Carr A, Cooper, DA. Adverse effects of antiretroviral therapy. Lancet 2000; 356: 1423-1430.

12. Liu S, Abbondanzieri EA, Rausch JW, Le Grice SF, Zhuang X. Slide into action: dynamic shuttling of HIV reverse transcriptase on nucleic acid substrates. Science 2008; 322: 1092-1097.

13. Abbondanzieri EA, Bokinsky G, Rausch JW, Zhang JX, Le Grice SF, Zhuang X. Dynamic binding orientations direct activity of HIV reverse transcriptase. Nature 2008; 453: 184.

14. Ghosh M, Jacques PS, Rodgers DW, Ottman M, Darlix JL, Le Grice SF. Alterations to the primer grip of p66 HIV-1 reverse transcriptase and their consequences for template-primer utilization. Biochemistry $1996 ; 35: 8553-8562$.

15. Thomas JA, Gorelick RJ. Nucleocapsid protein function in early infection processes. Virus Res 2008; 134: 39-63.

16. DE Clercq E. Novel compounds in preclinical/early clinical development for the treatment of HIV infection. Rev Med Virol 2000; 10: 255.

17. DE Clercq E. Antiviral drug discovery and development: where chemistry meets with biomedicine. Antiviral Res 2005; 67: 56-75.

18. De Clercq E. The discovery of antiviral agents: ten different compounds, ten different stories. Med Res Rev 2008; 28: 929-953.

19. Broder S, Gallo RC. Apathogenic retrovirus (HTLV-III) linked to AIDS. N Engl J Med 1984; 311: 1292-1297.

20. Martins S, Ramos MJ, Fernandes PA. The current status of the NNRTI family of antiretrovirals used in the HAART regime against HIV infection. Curr Med Chem 2008; 15: 1083-1095.

21. Tsibris AM Hirsch MS. Antiretroviral therapy in the clinic. J Virol 2010; 84: 5458-5464.

22. Christopher AK, William L. Nucleoside reverse transcriptase inhibitor toxicity and mitochondrial DNA. Exp Opin Drug Metab Toxicol 2010; 6: 1493-1504.

23. Mitsuya H, Weinhold KJ, Furman PA, St Clair MH, Lehrman SN, Gallo RC. 30-Azido-30-deoxythymidine (BW A509U): An antiviral agent that inhibits the infectivity and cytopathic effect of human T-lymphotropic virus type III/lymphadenopathyassociated virus in vitro. Proc Natl Acad Sci U S A 1985; 82: 7096-7100.

24. Mitsuya H, Popovic M, Yarchoan R, Matsushita S, Gallo RC, Broder S. Suramin protection of T cells in vitro against infectivity and cytopathic effect of HTLVIII. Science 1984; 226: 172-174.

25. Mitsuya $\mathrm{H}$, Broder S. Inhibition of the in vitro infectivity and cytopathic effect of human T-lymphotrophic virus type III/lymphadenopathy-associated virus (HTLV-III/LAV) by 20, 30 dideoxy nucleosides. Proc Natl Acad Sci U S A 1986; 83: 1911-1915.

26. Cihlar T, Ray AS. Nucleoside and nucleotide HIV reverse transcriptase inhibitors: 25 years after zidovudine. Antiviral Res 2010; 85: 39-58. 
27. Schinazi RF, Lloyd RM, Nguyen MH, Cannon DL, McMillan A, Ilksoy N. Characterization of human immunodeficiency viruses resistant to oxathiolane-cytosine nucleosides. Antimicrob Agents Chemother 1993; 37: 875-881.

28. Sarafianos SG, Das K, Clark AD, Ding J, Boyer PL, Hughes SH. Lamivudine (3TC) resistance in HIV-1 reverse transcriptase involves steric hindrance with $\beta$-branched amino acids. Proc Natl Acad Sci 1999; 96: 10027-10032.

29. Arion D, Kaushik N, McCormick S, Borkow G, Parniak MA. Phenotypic mechanism of HIV-1 resistance to 3'-azido-3'-deoxythymidine (AZT): Increased polymerization processivity and enhanced sensitivity to pyrophosphate of the mutant viral reverse transcriptase. Biochemistry 1998; 37: 15908-15917.

30. Farzad F, Thompson DW, Kelly CA, Meyer GJ. Competitive intermolecular energy transfer and electron injection at sensitized semiconductor interfaces. J Am Chem Soc 1999; 121: 5577-5578.

31. Arts EJ, Hazuda DJ. HIV-1 antiretroviral drug therapy. Cold Spring Harbor Perspect Med 2012; 2: a007161.

32. Baba M, Pauwels R, Herdewijn P, De Clercq E, Desmyter J, Vandeputte $\mathrm{M}$. Both 20, 30-dideoxythymidine and its 20,30-unsaturated derivative (20, 30-dideoxythymidinene) are potent and selective inhibitors of human immunodeficiency virus replication in vitro. Biochem Biophys Res Commun 1987; 142: 128-134.

33. Hamamoto Y, Nakashima H, Matsui T, Matsuda A, Ueda T, Yamamoto N. Inhibitory effect of 2', 3'-didehydro-2', 3'-dideoxynucleosides on infectivity, cytopathic effects, and replication of human immunodeficiency virus. Antimicrob Agents Chemother 1987; 31: 907-910.

34. Tai-Shun L, Schinazi RF, Prusoff WH. Potent and selective in vitro activity of 3'-deoxythymidin-2'-ene (3'-deoxy-2'3'-didehydrothymidine) against human immunodeficiency virus. Biochem Pharmacol 1987; 36: 2713-2718.

35. Soudeyns H, Yao XI, Gao Q, et al. Anti-human immunodeficiency virus type 1 activity and in vitro toxicity of 20-deoxy-30-thiacytidine (BCH-189), a novel heterocyclic nucleoside analog. Antimicrob Agents Chemother 1991; 35: 1386-1390.

36. Schinazi RF, McMillan A, Cannon D, Mathis R, Lloyd RM, Peck A. Selective inhibition of human immunodeficiency viruses by racemates and enantiomers of cis-5-fluoro-1-[2-(hydroxymethyl)-1, 3-oxathiolan-5-yl]cytosine. Antimicrob Agents Chemother 1992; 36: 2423-2431.

37. Daluge SM, Good SS, Faletto MB, Miller WH, St Clair, MH, Boone LR. 1592U89, a novel carbocyclic nucleoside analog with potent, selective antihuman immunodeficiency virus activity. Antimicrob Agents Chemother 1997; 41: 1082-1093.

38. Farrokhi M, Gholami M, Mohraz M, McFarland W, Baesi K, Abbasian L. HIV drug resistance among naïve HIV-infected patients in Iran. J Res Med Sci 2019; 24: 31

39. Furman PA, Fyfe JA, St Clair MH, Weinhold K, Rideout JL, Freeman GA. Phosphorylation of 30-azido-30-deoxythymidine and selective interaction of the 50-triphosphate with human immunodeficiency virus reverse transcriptase. Proc Natl Acad Sci U S A 1986; 83: 8333-8337.

40. Branson BM, Handsfield HH, Lampe MA, et al. Centers for Disease Control and Prevention (CDC).Revised recommendations for HIV testing of adults, adolescents, and pregnant women in health-care settings. MMWR Recomm Rep 2006; 55 (RR-14): 1-17.

41. Lee S, Wood O, Tang S, et al. Detection of emerging HIV variants in blood donors from urban areas of Cameroon. AIDS Res Hum Retroviruses 2007; 23: 1262-1267.

42. Greenwald JL, Burstein GR, Pincus J, Branson B. A rapid review of rapid HIV antibody tests. Curr Infect Dis Rep 2006; 8: 125-131.

43. De Béthune MP. Non-nucleoside reverse transcriptase inhibitors (NNRTIs), their discovery, development, and use in the treatment of HIV-1 infection: a review of the last 20 years (1989-2009). Antiviral Res 2010; 85: 75-90.
44. Balzarini J, De Clercq E. Biochemical pharmacology of nucleoside analogs active against HIV. In: Broder S, Merigan TC, Bolognesi D (eds.). Textbook of AIDS Medicine. Baltimore, Md.: Williams \& Wilkins; 1994; 751-772.

45. Jochmans D, Vingerhoets J, Arnoult E, Geeraert L, Guillemont J. AntiviralResearch:Strategies in AntiviralDrug Discovery. Chapter 3: Human immunodeficiency virus type 1 non-nucleoside reverse transcriptase inhibitors. Washington: ASM Press; 2009; 33-50.

46. Sluis-Cremer N, Temiz NA, Bahar I. Conformational changes in HIV-1 reverse transcriptase induced by nonnucleoside reverse transcriptase inhibitor binding. Curr HIV Res 2004; 2: 323-332.

47. Balzarini J. Current status of the non-nucleoside reverse transcriptase inhibitors of human immunodeficiency virus type 1. Curr Top Med Chem 2004; 4: 921-944.

48. Podzamczer D, Fumero E. The role of nevirapine in the treatment of HIV-1 disease. Exp Opin Pharmacother 2001; 2: 2065-2078.

49. Seetaha S, Hannongbua S, Rattanasrisomporn J, Choowongkomon K. Novel peptides with HIV-1 reverse transcriptase inhibitory activity derived from the fruits of Quercus infectoria. Chem Biol Drug Design 2021; 97: 157-166.

50. Benso B, Rosalen PL, Pasetto S, Marquezin MC, Freitas-Blanco V, Murata RM. Malva sylvestris derivatives as inhibitors of HIV-1 BaL infection. Natural Product Research 2021; 135: 1064-1069.

51. Rimsky LT, Azijn H, Tirry I, et al. In vitro resistance profile of TMC278, a next generation NNRTI: evidence of a higher genetic barrier and a more robust resistance profile than first generation NNRTIs. Antiviral Ther 2009.

52. Moyle G, Boffito M, Manhard K, Sheedy B, Hingorani V, Yeh, LT. Antiviral activity of RDEA806, a novel HIV non-nucleoside reverse transcriptase inhibitor, in treatment of näive HIV patients. In: XVII $^{\text {th }}$ IAS Conference, Mexico City 2008.

53. Zala C, Murphy R, Zhou XJ, et al. IDX899, a novel HIV-1 NNRTI with high barrier to resistance, provides suppression of HIV viral load in treatment-naïve HIV-1-infected subjects. In: XVII ${ }^{\text {th }}$ International AIDS Conference, Mexico City 2008. 